Meeuwesen, L., Brink, A. van den, Hofstede, G.

Can dimensions of national culture predict cross-national differences in medical

communication? Patient Education and Counseling: 2009, 75(1), 58-66

\begin{tabular}{|l|l|}
\hline Postprint Version & 1.0 \\
\hline Journal website & http://www.pec-journal.com/article/S0738-3991(08)00530-2/abstract \\
\hline Pubmed link & $\underline{\text { http://www.ncbi.nlm.nih.gov/pubmed/19013047 }}$ \\
\hline DOI & $10.1016 /$ j.pec.2008.09.015 \\
\hline
\end{tabular}

This is a NIVEL certified Post Print, more info at http://www.nivel.eu

\title{
Can dimensions of national culture predict cross- national differences in medical communication?
}

\author{
LUdWIEN MEeuWESEN $^{\mathrm{A}}$, ATIE VAN DEN BRINK-MUINEN ${ }^{\mathrm{B}}$ AND GEERT HofSTEDE $^{\mathrm{C}}$ \\ anterdisciplinary Social Science Department, Utrecht University, Research Institute for \\ 'Psychology \& Health', P.O. Box 80.140, 3508 TC Utrecht, The Netherlands \\ ${ }^{\mathrm{b}}$ Netherlands Institute for Health Services Research (NIVEL), Research Institute for \\ 'Psychology \& Health', Utrecht, The Netherlands \\ ${ }^{\mathrm{c}}$ Professor Emeritus of Organizational Anthropology and International Management at \\ Maastricht University, Maastricht, The Netherlands
}

\begin{abstract}
Objective: This study investigated at a country level how cross-national differences in medical communication can be understood from the first four of Hofstede's cultural dimensions, i.e. power distance, uncertainty avoidance, individualism/collectivism and masculinity/femininity, together with national wealth.
\end{abstract}

Methods: A total of 307 general practitioners (GPs) and 5820 patients from Belgium, Estonia, Germany, Great Britain, the Netherlands, Poland, Romania, Spain, Sweden and Switzerland participated in the study. Medical communication was videotaped and assessed using Roter's interaction analysis system (RIAS). Additional context information of physicians (gender, job satisfaction, risk-taking and belief of psychological influence on diseases) and patients (gender, health condition, diagnosis and medical encounter expectations) was gathered by using questionnaires.

Results: Countries differ considerably form each other in terms of culture dimensions. The larger a nation's power distance, the less room there is for unexpected information exchange and the shorter the consultations are. Roles are clearly described and fixed. The higher the level of uncertainty avoidance, the less attention is given to rapport building, e.g. less eye contact. In 'masculine' countries there is less instrumental communication in the medical interaction, which was contrary to expectations. In wealthy countries, more attention is given to psychosocial communication.

Conclusion: The four culture dimensions, together with countries' wealth, contribute importantly to the understanding of differences in European countries' styles of medical communication. Their predictive power reaches much further than explanations along the north/south or east/west division of Europe. 
Practice implications: The understanding of these cross-national differences is a precondition for the prevention of intercultural miscommunication. Improved understanding may occur at microlevel in the medical encounter, as well as on macrolevel in pursuing more effective cooperation and integration of European health care policies.

\section{INTRODUCTION}

The last decade has shown a growing interest in cross-national studies in medical communication in European health care, due to worldwide migration as well as ongoing European harmonisation and integration of health care policies and cooperation in health care [1], [2], [3], [4], [5], [6], [7], [8] and [9]. Strengthening the role of primary care is one of the aims of European health care policy [10]. Although the number of these cross-national publications is growing, studies which incorporate cultural dimensions of nations are mostly lacking [11]. The present study tries to fill this gap. Nations may differ substantially in norms, values and behaviour [12], [13] and [14], which seem to play an important role in medical health care too [6], [15], [16] and [17]. Knowledge about these differences may contribute importantly to the prevention of cross-national miscommunication and to effective cooperation and integration of health care policies.

The aim of this study is to investigate how differences in the communicative behaviour of general practitioners (GPs) and patients can be understood by cultural dimensions on a national level in 10 European countries (Belgium, Estonia, Germany, Great Britain, The Netherlands, Poland, Romania, Spain, Sweden and Switzerland).

Before discussing existing literature about these communicative differences (see Section 1.2), attention will be paid to cultural approaches. Differences between societies' health care systems cannot be studied in isolation from their cultural and social aspects. The cultural aspects refers to the entire knowledge a human being needs to function adequately in a given situation (a group, (sub)culture, nation, etc.) [18]. Hofstede [19] introduced the term 'mental programming' to refer to the internalisation of these cultural processes. This common knowledge also refers to the health care system, which turns out to differ across countries.

\subsection{Dimensions of national culture}

To approach conceptually a nations' culture, we applied Hofstede's dimensions, which developed from research in one multinational business corporation in 40 countries [19] and now extend to 74 countries [20]. Hofstede defines values as broad tendencies to prefer certain state of affairs over others. The research showed that similar respondents in different countries use different solutions to the same four basic problems: (1) social inequalities, (2) dealing with the impredictable, (3) relation between individual and group, and (4) emotional role division between the genders. Based on these findings, Hofstede formulated four dimensions of national culture, labelled as power distance, uncertainty avoidance, individualism-collectivism, and masculinity-femininity. Later, a fifth dimension, long-term orientation was added. Box 1 contains the definitions of these dimensions.

\section{[BOX 1]}

Survey studies of large samples of similar respondents in different countries enabled Hofstede and others to attach indices (on a continuum between 100 and 0 ) to countries on these five dimensions. The indices describe societies and should not be applied to individuals. The dimensions are extensively validated against other aspects of national societies as well as tests of their cross-time stability [13]. Table 1 contains the scores on the five dimensions, as assessed by Hofstede [20], for the 10 countries included in present study. Countries' wealth is added, as it may be a potential confounder (see Section 2). 


\section{[TABLE 1]}

The 10 participating European countries differ considerably in their power distance, uncertainty avoidance, individualism, masculinity and wealth, but less in their long (short)term orientation. For example, Romania scores high on power distance as well as uncertainty avoidance, and is quite collectivistic. Poland is lower than Romania on power distance, and more individualistic. Great Britain scores highly individualistic with a lower power distance, and fairly masculine. Other equally wealthy countries like the Netherlands and Sweden resemble Great Britain, except that both score very feminine. Belgium resembles the Netherlands on individualism, but is more similar to Poland with regard to power distance. Spain and Great Britain score quite short-term oriented, while the Netherlands and Switzerland score somewhat longer term.

The intercorrelations (Table 2) show that across these 10 countries a larger power distance goes hand in hand with higher levels of uncertainty avoidance, with more collectivism, and with less wealth. Wealth is related to individualism. The more individualistic a country is, the smaller the power distance and the weaker the uncertainty avoidance. These correlations are specific to the present sample of European countries, and could have looked different if countries of other continents would have been included [13].

\section{[TABLE 2]}

\subsection{Dimensions of culture related to medical communication}

Although the Hofstede dimensions arose in the domain of industrial psychology, they deal with issues that seem equally relevant to medical psychology and health care. For example, some relevant connotations related to power distance could be hierarchical versus equalitarian relations in doctor-patient communication, degree of conformism, information exchange, and shared decision-making; for uncertainty avoidance these could be patient's emotionality or anxiety and stress, doctor's task-orientation, preference for technological solutions, belief in specialists, doctor's uncertainty avoidance, degree of medicalisation; for individualism they could be patient autonomy, possibility of choice, flexibility of social roles, less conformity, and psychosocial information exchange; masculinity could be associated with instrumental (or curing) behaviour, disease centred communication, biomedical talk, and doctor's gender; and long (or short)-term orientation with futureorientedness (like prevention) or symptom orientedness [9], [13], [19], [21], [22], [23] and [24]. From a culture theoretical approach, the present study enables tracing which cultural factors are related to medical communication and context characteristics in health care. Countries differ in the degree to which primary care professionals function as gatekeepers, patient expectations, doctor's beliefs and attitudes, medical communication in terms of consultation length and instrumental versus affective behaviour, and diagnosis [1], [8], [10] and [25]. Until now, explanations from a cultural perspective are mostly lacking, and those according to the east-west or north-south axis are not sufficient. For example, Polish doctors are more directive and verbally dominant compared to North-American colleagues, but also much warmer, by expressing positive feelings towards the patients [26]. They may be described as 'warm autocrats' compared to North American 'cold experts'. Poland has a larger power distance compared to the U.S. There is some indication that medical communication in the U.S. and the U.K. is somewhat more instrumental (i.e. more masculine) compared to the Netherlands [27]. Further, Belgian doctors are rather diseasecentred, and Dutch doctors are more patient-centred, while doctors in the U.K. are inbetween [24]. Japanese consultations are more instrumental compared to North American consultations in general [15]. On diagnostics, some countries have specific diseases, that have no clear equivalents elsewhere - for example crise de foie (liver problems) in France, Herzinsufficienz and Kreislaufkollaps (blood circulation problems) in Germany, or a variety of chills and obsessions with bowel movements in the U.K. [17]. Further, more traditional values were related to lower prevalence of psychiatric morbidity compared to countries 
holding more modern values [21]; there seems to be more preference for folk-illnesses thj [6]. Together with the observations of cross-national differences in presentation of complaints by patients [28], these data suggest that a country's specific cultural context seems to play a prominent role in (the results of) medical communication [6].

Based on the concepts underlying the cultural dimensions, on the scores of the Hofstede dimensions for the 10 participating countries, and on the findings of cross-national differences on medical communication described above, a number of expectations can be formulated:

1. In countries with a larger power distance, consultations will be shorter, patients will speak less, patient and doctor roles are more fixed, patient expectations regarding the medical encounter will be more uniform, and there will be less opportunity for unexpected information exchange compared to countries with a smaller power distance.

2. The stronger a countries' uncertainty avoidance, the more instrumental talking, the less affective talking and the more biomedical exchange can be expected.

3. In individualistic (wealthier) countries there will be more exchange of psychosocial information.

4. The more masculine a country, the more instrumental (curing or disease-centred) communication will dominate, the less attention will be paid to psychosocial issues and the more frequently doctors will be men.

\section{METHODS}

\subsection{Type of study and data collection}

The study was cross-sectional, and based on a secondary analysis of data of two Eurocommunication studies [7] and [10]. These data were gathered from 1999 to 2001. The sampling method differed from one country to another, on account of the varying willingness of GPs to participate, or for other practical reasons. The GPs are representative of the entire GP population in each participating country, as was shown by a comparison with the study population of the task profile study, with some exceptions [29]. Patients consulting a participating GP on the day(s) of the data collection were approached randomly. Both the GPs and the patients signed an informed consent form. The non-response rate of patients was $7.8 \%$. Non-response analysis showed that the representativeness was satisfying in nearly all respects. A total of 307 GPs and 5820 patients participated in the study.

The data (outcome measures) were derived from observations of video consultations, analysis of patient and GP questionnaires and GP registration. The instruments, the scale composition and the reliability of the measurements are described in detail elsewhere [7], [8] and [10]. The instruments can be summarized as follows. In the GP questionnaire information was collected about subjects including demographics, the GP's experience of general practice, and practice characteristics. The GPs filled in the questionnaire in their own language. For the patient questionnaires researchers from the participating countries translated the questionnaires from English to their own language. Afterwards, they were back-translated into English by professional translators. The questionnaires included items on demographics, health condition and expectations. The video observations included the RIAS coding (see Section 2.3.4) and a number of consultation characteristics, such as consultation length, patient utterances and eye contact (see Section 2.3.3). All these observations were performed by two trained research assistants.

\subsection{Predictor variables}

The predictor variables were Hofstede's five dimensions of national culture, i.e. power distance index (PDI), uncertainty avoidance index (UAI), individualism-collectivism index (ICI), masculinity-femininity index (MFI), and long (or short)-term orientation index (LSTO). A sixth predictor, national wealth, was added to the design, because a country's wealth may be a potential confounder [11] and [13]. As better resources allow more people 
Meeuwesen, L., Brink, A. van den, Hofstede, G.

Can dimensions of national culture predict cross-national differences in medical

communication? Patient Education and Counseling: 2009, 75(1), 58-66

to achieve their goals, and as higher education and income confer higher status and more knowledge, it is likely that individuals and nations with higher incomes will behave differently when interacting. The scores of the five cultural dimensions per country were derived from Hofstede and Hofstede [20], and lie on a continuum between 100 and 0 ; the scores for the 10 participating countries of the present study lie between 94 and 5 . The higher the score, the higher the power distance, uncertainty avoidance, individualism, masculinity and long-term orientation, respectively. National wealth was operationalised as the per capita income of nations in terms of the purchasing power of individuals [30]. Data are given in Table 1.

\subsection{Outcome variables}

The effect of the six independent variables was assessed on a series of relevant health carerelated variables in primary care (a total of 34), derived from the observations and questionnaires of the two Eurocommunication studies as mentioned [7] and [10].

The included variables were divided into context variables and medical communication variables. The context variables included four doctor items (gender, job satisfaction, risktaking and belief of psychological influence on diseases), four patient items (health condition, diagnosis, medical encounter expectations in biological terms, and medical encounter expectations in psychosocial terms), and three consultation characteristics (eye contact, consultation length and patient utterances). The medical communication variables included patients' affective and instrumental behaviour (10 items), and doctor's affective and instrumental behaviour (12 items).

\subsubsection{Context variables, doctor (4 items)}

1. GPs' gender as percentage of male doctors included in the present study.

2. G's job satisfaction was measured on a 7 item scale, with five answer categories [31] and [32]. The higher the score, the more satisfied the doctors are.

3. GPs' risk-taking in medical decision-making was based on a 5 item scale, adapted for this study [23]. The higher the score, the more risk-taking (such as waiting, no immediate treatment) will take place. Risk-taking needs to be regarded mainly as 'wait and see'.

4. GPs' beliefs of psychological influence on diseases: the degree to which doctors think that psychosocial factors might influence the onset or acute exacerbation of disorders was measured by a 12 item scale [32]. The higher the score, the greater doctors' belief in psychosocial influence.

\subsubsection{Context variables, patient (5 items)}

5. Patients' gender as percentage of male patients included in the present study.

6. Patients' health condition: patients' perception of their overall health condition was questioned by an item ('during the past 2 weeks, how would you rate your health in general?', answered on a 5-point scale) derived from the COOP/WONCA charts, and validated for cross-national use [33]. Originally, the lower the score, the better patients' health. These scores are recoded in the present study: the higher the score, the better patient's general health condition.

7. Patients' diagnosis: patients' diagnosis was coded according to the International Classification of Primary Care [34]. The diagnoses were labelled as either psychosocial (psychological and social) or not.

8/9. Patients' expectations of the medical encounter: to measure patients' expectations regarding the medical encounter, a 10-item scale was used dealing with the expectations and performance of communication aspects. This scale was based on the combining and adaptation of the Quote scale [35] and the patient request form [8] and [36]. Factor analysis of questions on expectations and performance revealed two subscales: a biomedical scale of 6 items and a psychosocial scale of 4 items. Correspondence and discrepancy between expectations and performance was calculated. Correspondence was defined if items were 
Meeuwesen, L., Brink, A. van den, Hofstede, G.

Can dimensions of national culture predict cross-national differences in medical

communication? Patient Education and Counseling: 2009, 75(1), 58-66 expected as well as performed, or if items were neither expected nor performed. Discrepantyel
was applicable if items were expected but not performed, or if performed items were not expected. This resulted in two items: Percentage correspondence between expectations and performance on biomedical issues, as well as on psychosocial issues. These two variables are an indicator for the anticipation of roles and behaviour in the specific medical context.

\subsubsection{Context variables, consultation characteristics (3 items)}

10. Consultation length: measured in minutes and seconds.

11. Patient utterances: to measure the conversational contribution of the patients, the patient utterances relative to the total count of utterances of both GPs and patients were counted. Percentages were used by dividing patient utterances by the total of all (GP and patient) utterances. Utterances - as unit of analysis - were based on the RIAS coding (see below).

12. Eye contact: eye contact between doctor and patient was measured by GPs' patient directed gaze, i.e. the time the GP looked directly into the patient's face. This was rated by stopwatch. The length of time of eye contact was related to the length of time the GP is sitting opposite the patient, in other words the length of time the GP was 'on the screen' and was able to look at the patient.

\subsubsection{Verbal behaviour, 12 doctor items and 10 patient items}

\subsubsection{Verbal affective and instrumental behaviour of doctor and patient}

Data about doctor-patient communication were derived from videotapes of the consultations and assessed by Roter's interaction analysis system (RIAS) [7], [10] and [37]. The system differentiates both affective (socio-emotional) and instrumental (task-focussed) verbal behaviour in doctors and patients, reflecting the care-cure dimension. The RIAS, which was based on the work of Bales [38], enables the identification, categorisation and quantification of salient features of doctor-patient communication. The unit of analysis is an utterance or the smallest meaningful string of words. All utterances were assigned to mutually exclusive categories. The consultations were rated by means of a computerized rating method named OBSERVER [39].

The same person trained each group of (at least two) observers in each country in the same way, with the aim of achieving equivalent ratings of the videotaped consultations in all countries. Observers were always native speakers (with a university education). Inter-rater reliability was measured for each country separately, by calculating Pearson's correlation coefficient for 20 consultations of different doctors rated by pairs of observers. It appeared that $79 \%$ of inter-rater reliabilities were quite good ( 0.7 or higher), $15 \%$ were moderately good (between 0.5 and 0.7$)$ and $6 \%$ were too low $(<0.5)$, especially for the 'other utterances' category. The content validity and discriminant validity of the RIAS have been proven to be satisfactory [40].

All behaviour was merged into 10 clusters for the doctors and 8 for the patients. The affective dimension included social behaviour, agreement (mainly backchannelling like ' $\mathrm{hm}$ '), rapport-building (verbal attention, showing concern, reassurance) and facilitation (paraphrasing and clarification) for both patients and doctors. The instrumental dimension contained orientation (giving directions) (only doctors), asking questions, giving information, counselling (only doctors). Communication categories were expressed as percentages of the total number of utterances of GPs and patients, respectively.

Further, while the content of questions, information conveyance and counselling was coded as biomedical or psychosocial, two items were added: biomedical talk and psychosocial talk. Based on these two items, a ratio of biomedical/psychosocial talk was calculated too, for both doctors and patients. Lastly, a ratio for instrumental/affective behaviour was calculated 
Meeuwesen, L., Brink, A. van den, Hofstede, G.

Can dimensions of national culture predict cross-national differences in medical

communication? Patient Education and Counseling: 2009, 75(1), 58-66

for doctors and patients. In sum, this resulted in 12 doctor items and 10 patient items

regarding verbal behaviour.

\subsection{Analyses}

A check for normal distribution of the variables was performed, and some variables with non-normal distributions (power distance index, wealth, consultation length) were transformed mathematically to enable parametric statistics. Stepwise regression analysis was performed to find the strongest predictors for the separate outcome measures. The adjusted $R^{2}$ are presented instead of the normal $R^{2}$ values, because of the small sample $(n=10)$. For the same reasons, the $p$-value was set at $10 \%$ instead of $5 \%$. The dimension 'long versus short-term orientation' was left out of these analyses, as there was little variance among the countries, and two countries had no data at all. Based on these results, an ecological factor analysis was done with the most relevant outcome variables $(n=27)$. Because this is an ecological factor analysis, based on data at the level of countries which are different from individual factors, the number of cases need not be larger than the number of variables. The stability of the results of ecological factor analysis is not determined by the number of aggregated cases, but by the number of individuals whose scores are aggregated into these cases [12]. This factor analysis included 27 outcome variables instead of the original 34; seven variables were excluded because of collinearity (if $r>.85$ ). It generated four communication styles, together explaining $79 \%$ of the variance (Table 3 ).

\section{[TABLE 3]}

Factor 1, Fixed communication roles, included 8 items focusing on highly predictable roles in the medical encounter, shorter consultation length, and less question-asking and information conveyance, doctors' facilitating the communication and patients' rapportbuilding. A lower percentage of male patients and lower subjective health of patients were also included.

Factor 2, Biomedical information exchange, included 7 items related to instrumental behaviour, expressed by physicians' question-asking and biomedical talk and by patients' question-asking and information conveyance, together with physicians' lower job satisfaction.

Factor 3, Rapport-building, contained 6 items high on eye contact and doctors' rapportbuilding, and lower on social talk and providing orientation.

Factor 4, Psychosocial information exchange, had 5 items, and focused on the exchange of psychosocial information, together with doctors' risk-taking and their belief in psychosocial influences on the patient's disease.

Finally, a stepwise regression of the five predictors on these four communication styles was performed.

\section{RESULTS}

\subsection{Context variables}

Table 4 shows the regression effects of the predictors on the context variables.

\section{[TABLE 4]}

In countries where the power distance is larger (such as Romania, Poland and Belgium), patients' psychosocial expectations were closely met during the medical encounter. This is an indication for rather fixed roles regarding the exchange of psychosocial information.

In countries scoring high on uncertainty avoidance, physicians were less satisfied with their job. There was a stronger belief in psychosocial influences on the patient's disease. Further, physician and patient had less eye contact in the medical encounter (Belgium, Romania and Spain). 
The largest effects were from the dimension individualism/collectivism, on biomedical nivel $^{-}$ expectations of patients: the more individualistic a country was the less concordance between expectations and performance. This is an indication of more flexible doctor and patient roles. Further, the more individualistic, the more importance physicians attached to psychosocial influences on the disease. This is strengthened by strong uncertainty avoidance (like in Belgium). Physicians also took more risks ('wait and see') in individualistic countries. At last, in the more individualistic countries, a higher share of the patients consulting the GP were male.

Sometimes, a country's wealth was a stronger predictor than individualism: richer countries had more male physicians, better health condition of patients, more psychosocial diagnoses, longer consultations and greater conversational attribution of patients.

The dimension masculinity/femininity did not show any effect on the context variables.

\subsection{Physicians' verbal behaviour}

Physicians showed more social talk in higher power distance countries, but less backchannelling (both affective talk). They gave more orientation to their patients, which is seen as instrumental behaviour (Table 5). Physicians of countries high on uncertainty avoidance tended to pay more attention to psychosocial talk with the patients.

\section{[TABLE 5]}

The largest effects were shown in the individualism/collectivism dimension. The more individualistic a nation was, the more backchannelling (' $\mathrm{hm}$ ') were given by the physician, and the more information was given. Physicians asked relatively fewer questions to patients and did less counselling in more individualistic countries (UK, Netherlands and Belgium). In sum, the more individualistic a country, the more affective behaviour is shown by physicians.

Contrary to expectations, it is observed that in more masculine than feminine countries physicians showed more social talk and agreements, talking relatively less about biomedical issues.

\subsection{Patients' verbal behaviour}

The smaller the power distance in a country, the more backchannels the patients gave (e.g. Switzerland). In countries with strong uncertainty avoidance more agreements ('hm' or 'yes') were given by patients (Table 6).

\section{[TABLE 6]}

The more masculine a country was, the more social talk, backchannelling and facilitation the patients gave. However, the more feminine a country was, the more information patients gave, and the more biomedical talk. In sum, in more masculine countries there is relatively more affective than instrumental patient talk, which was not expected.

\subsection{Communication styles}

Countries' power distance explained $72 \%$ of the Fixed communication roles (Table 7): a larger power distance produced more correspondence between expectation and evaluation, more fixed doctor and patient roles, less information conveyance by the doctor, more female patients, poorer patient health, shorter medical encounters, and fewer doctors' facilitating their patients and providing counselling. Conversely, in countries with smaller power distance, there will be more chances of a flexible communication style, with doctors' greater information conveyance to patients. This is according to our expectation.

\section{[TABLE 7]}

The level of uncertainty avoidance explained $41 \%$ of Rapport-building. Countries with a higher tolerance for uncertainty, had more eye contact and paid more attention to rapport 
building. Doctors seemed to be more open to their patients. Psychosocial information

exchange was also explained by uncertainty avoidance (step 2, up to $44 \%$ ).

Countries' masculinity explained $64 \%$ of the Biomedical information exchange (and instrumental communication). The more feminine a country the more instrumental communication there was: there was a lot of question-asking, by both doctor and patient, and much biomedical information exchange. Accordingly, physicians were less satisfied with their jobs. These results on instrumental communication are contrary to our expectations: in masculine countries there is more affective communication than instrumental communication, and doctors seem to be more satisfied.

Psychosocial information exchange was explained by countries' wealth (step 1, 25\%). The wealthier a country was, the more psychosocial issues were discussed, by both doctor and patient; patients had room to express their concerns and worries, and doctors were prone to take more risks. This effect was enhanced by the degree of uncertainty avoidance: the more uncertainty avoidance, the more psychosocial exchange of information. The expectation that in wealthier (individualistic) countries medical communication is characterized by more psychosocial talk is supported by this result.

\section{DISCUSSION AND CONCLUSION}

\subsection{Discussion}

This study shows that cultural dimensions allow prediction of cross-national variation in medical communication at a country level. First, the dimension of power distance is, according our expectations, positively associated with fixed roles of physician and patient. In countries like Romania, Poland, Belgium and Spain, patients get what they expect, and these consultations are shorter than in low power distance countries (the five western European countries and Estonia). Second, these same countries, high on uncertainty avoidance, pay less attention to rapport-building, compared to Great Britain, Sweden and Estonia, while countries like Germany, the Netherlands and Switzerland are in-between. Third, the finding regarding high exchange of psychosocial information in individualistic countries was also according our expectations, even though countries' wealth overruled the individualism/collectivism dimension, and despite the contribution of level of uncertainty avoidance. As we have seen, there is a substantial correlation between individualism and national wealth. Former results [21] on the importance given to psychosocial issues in more modern (i.e. the more wealthy and individualistic) countries are confirmed. Fourth, the results on the masculinity dimension run contrary to expectations that GPs of the more masculine countries would express more of instrumental and biomedical talk [13] and [20]. Surprisingly, in the more feminine countries there is more biomedical talk, which goes hand in hand with a relatively more instrumental communication style. Countries like Sweden, the Netherlands and Estonia seem to be far more instrumental and biomedical than Switzerland, Germany, Great Britain, Poland or Belgium. One may argue that the more 'feminine' countries may have ample outlets for emotions, thereby rendering such interventions unnecessary in a medical situation. In 'masculine' countries there may not be such outlets, therefore they are necessary in a medical context. Another plausible explanation has to do with substantial changes in the organisation of primary care in recent decades. Dutch data show that there is a shift towards a more businesslike, task-oriented style in GP communication, with a greater focus on biomedical aspects and much less on psychosocial issues due to the recent emphasis on evidence-based medicine and protocollised care [41]. This is reflected in the data, at least for some countries.

Before drawing conclusions, additional theoretical and methodological comments need to be made. The Eurocommunication Study I showed that healthcare system characteristics at the macrolevel (GP as gatekeeper versus freely accessible specialist care; fixed patient lists; salaried employment versus self-employment; fee-for service payment system versus a capitation system or a mixed payment system) are less important than microlevel factors in 
explaining differences in doctor-patient communication. It was concluded that the relationship between macro and microlevel characteristics is more complicated than has been assumed [7]. The Eurocommunication Study II showed that the communication patterns in the new EU-countries Estonia, Poland and Romania partly differed from the old EUcountries (of the first study), but most differences did not occur along a new-old or east-west divide. It appears that the new EU-member states cannot be considered to constitute a group of countries with similar communication patterns, although their health care systems are rather similar and are in a process of transition from centralized state systems (Semashko model) to a Western model [10]. The present study shows that cultural norms, values, beliefs and attitudes towards health and health care may influence the communication between doctors and their patients too and, therefore, the quality of health care and the patients' health.

Regarding the culture dimensions of Hofstede, one may argue that the context and time period of their development were quite different, i.e. research on big company employees in a profit sector versus high-status health care professionals working on a small scale in the non-profit sector. As the theory on cultural differences claims to be applicable to all kinds of settings and groups of people, it is argued that the dimensions, containing the fundamental issues nations have to cope with, are applicable in these non-profit contexts as well. The results of the present study sustain this, as well as other research in the health care context, such as a study on subjective well-being compared across 35 countries [11]. Recent work [13] and [20] shows that, although changes take place over time, the features of countries in these cultural terms seem to be quite stable over time. This is confirmed in the present study, except for the masculinity dimension.

This study does not permit to draw conclusions on the behaviour of individual physicians or patients. Because the focus was on aggregated data at a national level, it allows making statements on differences at that level. When making statements regarding the many crossnational differences, one must also realise that there are large regional differences even within countries, such as the different linguistic provinces of Belgium or Switzerland [6]. Further, the number of cases (nations) was limited to 10, which is rather small. A larger sample would have made it possible to draw firmer conclusions.

\subsection{Conclusion}

Cultural dimensions like power distance, uncertainty avoidance, individualism and masculinity, together with countries' wealth, seem to be better and more nuanced predictors of cross-national differences in health care communication than explanations along the north-south or east-west division of Europe. National differences in communication styles found among the participating countries in this study will provoke reflections in these countries on the role of communication training in medical curricula from the viewpoint of cultural dimensions.

\subsection{Practice implications}

Increased knowledge of nations' cultural norms and values on medical communication may contribute to improved mutual understanding between European countries. The benefits may take place at medical encounter level, were the doctor-patient interaction takes place, as well as on macrolevel were negotiations occur towards striving for more effective cooperation and integration of European health care policies.

\section{REFERENCES}

[1] M. Deveugele, A. Derese, D. de Bacquer, A. van den Brink-Muinen, J. Bensing and J. de Maeseneer, Is the communicative behavior of GPs during the consultation related to the diagnosis? A cross-sectional study in six European countries, Patient Educ Couns 54 (2004), pp. 283-289.

[2] Migrant Health in Europe. Ethnicity \& Health, 2004; 9:S1. 
Meeuwesen, L., Brink, A. van den, Hofstede, G.

Can dimensions of national culture predict cross-national differences in medical

communication? Patient Education and Counseling: 2009, 75(1), 58-66

[3] L.A. Cooper, D.L. Roter, R.L. Johnson, D.E. Ford, D.M. Steinwachs and N.R. Powe,

Patient-centered communication, ratings of care, and concordance of patient and physician race, Ann Intern Med 139 (2003), pp. 907-915.

[4] J.A.M. Harmsen, When cultures meet in medical practice [Dissertation], Erasmus University Rotterdam, Rotterdam (2003).

[5] L. Meeuwesen, H. Harmsen, R. Bernsen and M. Bruijnzeels, Do Dutch doctors communicate differently with immigrant patients than with Dutch patients?, Soc Sci Med 63 (2006), pp. 2407-2417.

[6] C.G. Helman, Culture, health and illness (4th ed.), Butterworth-Heinemann, Oxford (2001).

[7] A. van den Brink-Muinen, P. Verhaak, J. Bensing, O. Bahrs, M. Deveugele, L. Gask, N. Mead, F. Leiva-Fernandes, A. Perez, V. Messerli, L. Oppizzi and M. Peltenburg, The Eurocommunication study: an international comparative study in six European countries on doctor-patient communication in general practice, NIVEL, Utrecht (1999).

[8] A. van den Brink-Muinen, P. Verhaak, J. Bensing, O. Bahrs, M. Deveugele, L. Gask, F. Leiva, N. Mead, V. Messerli, L. Oppizzi, M. Peltenburg and A. Perez, Doctor-patient communication in different European health care systems: relevance and performance from the patients' perspective, Patient Educ Couns 39 (2000), pp. 115-127.

[9] G. Lueschen, F. Stevens, J. van der Zee, W.C. Cockerham, J. Diederijks, A. d'Houtaud, M.G. Ferrando, R. Peeters and S. Niemann, Health care systems and the people: A fivenation study in the European Union, Int Sociol 9 (1994), pp. 337-362.

[10] A. van den Brink-Muinen, A. van Dulmen, J. Bensing, H.-I. Maaroos, H. Tähepöld, Z. Krol, L. Plawecki, S. Oana, M. Boros, U. Sätterlund-Larsson and B.-M. Bengtsson, Eurocommunication II. A comparative study between countries in Central-Europe and Western-Europe on doctor-patient communication in general practice, NIVEL, Utrecht (2003).

[11] W.A. Arrindell, C. Hatzichristou, J. Wensink, E. Rosenberg, B. van Twillert, J. Stedema and D. Meijer, Dimensions of national culture as predictors of cross-national differences in subjective well-being, Pers Indiv 23 (1997), pp. 37-53.

[12] R.E. Nisbett, The geography of thought: how Asians and westerners think differentlyand why, Nicholas Brealey, London (2003).

[13] G. Hofstede, Culture's consequences: comparing values, behaviors, institutions, and organizations across nations (2nd ed.), Sage, Thousand Oaks (2001).

[14] H.C. Triandis, Individualism and collectivism, Westview, Boulder, CO (1995).

[15] S. Ohtaki, T. Ohtaki and M.D. Fetters, Doctor-patient communication: a comparison of the USA and Japan, Fam Pract 20 (2003), pp. 276-282.

[16] M. Maclachlan, Cultivating pluralism in health psychology, J Health Psychol 5 (2000), pp. 373-382. )

[17] L. Payer, Medicine and culture: notions of health and sickness in Britain, the U.S., France and West Germany, Victor Gollancz, London (1988).

[18] W.A. Shadid, Grondslagen van interculturele communicatie: Studieveld en werkterrein (Principles of intercultural communication), Houten/Diegem, Bohn, Stafleu en Van Loghum (1998).

[19] G. Hofstede, Culture's consequences: international differences in work-related values, Sage, Beverly Hills, CA (1980).

[20] G. Hofstede and G.J. Hofstede, Cultures and organizations: software of the mind ([Revised and expanded 2nd edition]), McGraw-Hill, New York (2005).

[21] A. Märcker, Association of cross-cultural differences in psychiatric morbidity with cultural values: a secondary data analysis, German J Psychiatry 4 (2001), pp. 19-23.

[22] W.G.W. Boerma and D.M. Fleming, The role of general practice in primary health care, WHO (1998).

[23] R. Grol, M. Whitfield, J. de Maeseneer and H. Mokkink, Attitudes to risk taking in medical decision making among British, Dutch and Belgian general practitioners, Brit J Gen Pract 40 (1990), pp. 134-136. View Record in Scopus | Cited By in Scopus (35)

[24] R. Grol, J. de Maeseneer, M. Whitfield and H. Mokkink, Disease-centred versus patientcentred attitudes: comparison of general practitioners in Belgium, Britain and the Netherlands, Fam Pract 7 (1990), pp. 100-103. 
Meeuwesen, L., Brink, A. van den, Hofstede, G.

Can dimensions of national culture predict cross-national differences in medical

communication? Patient Education and Counseling: 2009, 75(1), 58-66

[25] M. Deveugele, A. Derese, A. van den Brink-Muinen, J. Bensing and J. de Maeseneerịvel Consultation length in general practice: cross sectional study, Brit Med J 325 (2002), pp.

472-474.

[26] I. Heszen-Klemens and E. Lapinska, Doctor-patient interaction, patients health behavior and effects of treatment, Soc Sci Med 19 (1984), pp. 9-18.

[27] J.M. Bensing, D.L. Roter and R.L. Hulsman, Communication patterns of primary care physicians in the United States and the Netherlands, J Gen Intern Med 18 (2003), pp. 335342.

[28] I.K. Zola, Pathways to the doctor: from person to patient, Soc Sci Med 7 (1974), pp. 677-689.

[29] W.G.W. Boerma, P.P. Groenewegen and J. van der Zee, General practice in urban and rural Europe: the range of curative services, Soc Sci Med 47 (1998), pp. 445-453.

[30] World Bank Atlas; 2000: http://www.worldbank.org.

[31] W.G.W. Boerma, J. van der Zee and D.M. Fleming, Service profiles of general practitioners in Europe, Brit J Gen Practice 47 (1997), pp. 481-486.

[32] M. Whitfield, R. Grol and H. Mokkink, General practitioners opinions about their responsibility for medical tasks: comparison between England and the Netherlands, Fam Pract 6 (1989), pp. 274-278. View Record in Scopus | Cited By in Scopus (1)

[33] C. van Weel, C. Konig-Zahn, F. Touw-Otten, N.P. van Nuijn and B. Meyboom-De Jong, Measuring functional health status with the COOP/WONCA Charts: a manual, ERGHO/NCH, Wonca (1995).

[34] H. Lamberts and M. Wood, International classification of primary care, Oxford University Press, Oxford (1987).

[35] H.J. Sixma, J.J. Kerssens, C. van Kampen and L. Peters, Quality of care from the patients' perspective: from theoretical concept to a new measuring instrument, Health Expect 1 (1998), pp. 82-95.

[36] R. Valori, M. Woloshynowych, N. Bellenger, V. Aluvihare and P. Salmon, The patient requests form: a way of measuring what patients want from their general practitioner, $\mathrm{J}$ Psychosom Res 40 (1996), pp. 87-94.

[37] D.L. Roter, The Roter method of interaction process analysis: RIAS manual, The John Hopkins University, Baltimore (2001).

[38] R.F. Bales, Interaction process analysis, Addison-Wesley, Cambridge (1950).

[39] L.P. Noldus, R.J. Trienes, A.H. Hendriksen, H. Janden and R.G. Jansen, The Observer Video-Pro: new software for the collection, management and presentation of time structured data from videotapes and digital media films, Behav Res Methods Instrum Comput 32 (2000), pp. 197-206. View Record in Scopus | Cited By in Scopus (92)

[40] L.M.L. Ong, M.R.M. Visser, I.P.M. Kruyver, J.M. Bensing, A. van den Brink-Muinen, J.M.L. Stouthardt, F.B. Lammes and J.C.J.M. de Haes, The Roter interaction analysis system (RIAS) in oncological consultations: psychometric properties, Psycho-oncol 7 (1998), pp. 387-401.

[41] J. Bensing, F. Tromp, S. van Dulmen, A. van den Brink-Muinen, W. Verheul and F. Schellevis, Shifts in doctor-patient communication between 1986 and 2002: a study of videotaped General practice consultations with hypertension patients, Fam Pract 7 (2006), pp. 62-68.

This article is based on secondary analysis of data of the Eurocommunication-I study, which has been made possible by funding from the BIOMED-II research programme of the European Union (contract no. BMH4-CT96-1515), and of the Eurocommunication-II study, funded from the INCO-Copernicus programme of the European Union (contract no. ERBIC 15-CT98-0312). 


\section{BOX AND TABLES}

Box 1. Five culture dimensions, derived from Hofstede and Hofstede [20].

\begin{tabular}{|c|l|}
\hline Power distance & $\begin{array}{l}\text { The extent to which the less powerful members of institutions and } \\
\text { organizations within a country expect and accept that power is } \\
\text { distributed unequally (from small to large). }\end{array}$ \\
\hline $\begin{array}{c}\text { Uncertainty } \\
\text { avoidance }\end{array}$ & $\begin{array}{l}\text { The extent to which the members of a culture feel threatened by } \\
\text { ambiguous or unknown situations (from weak to strong). }\end{array}$ \\
\hline $\begin{array}{c}\text { Individualism vs. } \\
\text { collectivism }\end{array}$ & $\begin{array}{l}\text { Individualism stands for a society in which the ties between } \\
\text { individuals are loose: everyone is expected to look after himself or } \\
\text { herself and his or her immediate family only. Its opposite, } \\
\text { collectivism, stands for a society in which people from birth } \\
\text { onwards are integrated into strong, cohesive in-groups, which } \\
\text { throughout people's lifetime continue to protect them in exchange } \\
\text { for unquestioning loyalty. }\end{array}$ \\
\hline $\begin{array}{l}\text { Masculinity vs. } \\
\text { femininity }\end{array}$ & $\begin{array}{l}\text { Masculinity stands for a society in which emotional gender roles } \\
\text { are clearly distinct: men are supposed to be assertive, tough, and } \\
\text { focused on material success; women are supposed to be more } \\
\text { modest, tender, and concerned with the quality of life. Its opposite, } \\
\text { femininity, stands for a society in which emotional gender roles } \\
\text { overlap: both men and women are supposed to be modest, tender, } \\
\text { and concerned with the quality of life. }\end{array}$ \\
\hline $\begin{array}{l}\text { Long-term vs. } \\
\text { short-term } \\
\text { orientation }\end{array}$ & $\begin{array}{l}\text { Long-term orientation stands for the fostering of virtues oriented } \\
\text { towards future rewards, in particular perseverance, thrift, and } \\
\text { adapting to changing circumstances. Is opposite, short-term } \\
\text { orientation, stands for the fostering of virtues related to the past and } \\
\text { present, in particular respect for tradition, preservation of 'face', } \\
\text { and fulfilling social obligations. }\end{array}$ \\
\hline and
\end{tabular}


Meeuwesen, L., Brink, A. van den, Hofstede, G.

Can dimensions of national culture predict cross-national differences in medical communication? Patient Education and Counseling: 2009, 75(1), 58-66

Table 1.

Scores of the predictor variables for 10 countries; number of participating doctors and patients (derived from Hofstede and Hofstede [20]).

\begin{tabular}{|c|c|c|c|c|c|c|c|c|}
\hline Country & PDI & UAI & ICI & MFI & LSTO & GNP & GPs & Patients \\
\hline Belgium & 65 & 94 & 75 & 54 & 38 & 24,880 & 31 & 601 \\
\hline Estonia & 40 & 40 & 60 & 30 & - & 4,070 & 27 & 516 \\
\hline Germany & 35 & 65 & 67 & 66 & 31 & 25,140 & 43 & 889 \\
\hline Great Britain & 35 & 35 & 89 & 66 & 25 & 25,400 & 27 & 446 \\
\hline Netherlands & 38 & 53 & 80 & 14 & 44 & 25,200 & 31 & 579 \\
\hline Poland & 68 & 68 & 60 & 64 & 32 & 4,430 & 35 & 678 \\
\hline Romania & 90 & 90 & 30 & 42 & - & 1,680 & 30 & 576 \\
\hline Spain & 57 & 86 & 51 & 42 & 19 & 14,790 & 27 & 539 \\
\hline Sweden & 31 & 29 & 71 & 05 & 33 & 28,640 & 25 & 376 \\
\hline Switzerland & 34 & 58 & 68 & 70 & 40 & 40,150 & 31 & 620 \\
\hline Total & & & & & & & 307 & 5820 \\
\hline
\end{tabular}

$\mathrm{DI}=$ power distance index, $\mathrm{UAI}=$ uncertainty avoidance index, $\mathrm{ICI}=$ individualism collectivism index, MFI = masculinity femininity index, LSTO = long (short)-term orientation and GNP = per capita gross national product. A high number on each variable denotes a high score on the variable as named; GPs = number of participating GPs; patients $=$ number of participating patients.

Table 2.

Intercorrelations (Pearson) between five dimensions of national culture and wealth $(n=10)$.

\begin{tabular}{|c|c|c|c|c|c|}
\hline Measures & 1 & 2 & 3 & 4 & 5 \\
\hline 1 Power distance (PDI) & 1.00 & & & & \\
\hline 2 Uncertainty avoidance (UAI) & $.82^{* *}$ & 1.00 & & & \\
\hline 3 Individualism-collectivism (ICI) & $-.69^{*}$ & $-.56^{\mathrm{a}}$ & 1.00 & & \\
\hline 4 Masculinity-femininity (MFI) & .17 & .33 & .04 & 1.00 & \\
\hline 5. Long (or short)-term orientation (LSTO) & -.18 & -.08 & .38 & -.21 & 1.00 \\
\hline 6 Wealth (GNP) & $-.64^{*}$ & -.27 & $.55^{\mathrm{a}}$ & .18 & .47 \\
\hline
\end{tabular}


Meeuwesen, L., Brink, A. van den, Hofstede, G.

Can dimensions of national culture predict cross-national differences in medical

communication? Patient Education and Counseling: 2009, 75(1), 58-66

${ }^{\mathrm{a}} p<0.10$

${ }^{*} p<0.05$.

$p<0.01$.

Table 3.

Factor analysis (with varimax rotation) with 27 outcome measures, four factors.

\begin{tabular}{|c|c|c|c|c|c|}
\hline Variables & & 1 & 2 & 3 & 4 \\
\hline \multirow[t]{4}{*}{ GP } & Male & & & & \\
\hline & Job satisfaction & & -.525 & & \\
\hline & Risk-taking & & & & .732 \\
\hline & Psy infl & & & & .655 \\
\hline \multirow[t]{4}{*}{ Patient } & Male & -.703 & & & \\
\hline & Health & -.825 & & & \\
\hline & Corr. Bio & .914 & & & \\
\hline & Corr. Psy & .807 & & & \\
\hline \multirow[t]{3}{*}{ Encounter } & Length & -.552 & & & \\
\hline & $p$-Speak & & & & .777 \\
\hline & Eye contact & & & .995 & \\
\hline \multirow[t]{9}{*}{ GP communication } & Social & & & -.757 & \\
\hline & Rapport & & & .703 & \\
\hline & Facility & .756 & & & \\
\hline & Orient & & & -.614 & \\
\hline & Quest & -.654 & .669 & & \\
\hline & Info & -.902 & & & \\
\hline & Biotalk & & .766 & & \\
\hline & Psytalk & & & & .692 \\
\hline & Ratio in/af & & .874 & & \\
\hline \multirow[t]{4}{*}{ P communication } & Social & & & -.758 & \\
\hline & Rapport & .511 & & & \\
\hline & Facility & & & -.642 & \\
\hline & Quest & & .877 & & \\
\hline
\end{tabular}


Meeuwesen, L., Brink, A. van den, Hofstede, G.

Can dimensions of national culture predict cross-national differences in medical communication? Patient Education and Counseling: 2009, 75(1), 58-66

\begin{tabular}{|c|c|c|c|c|c|}
\hline Variables & & 1 & 2 & 3 & 4 \\
\hline & Info & & .802 & & \\
\hline & Psytalk & & & & .799 \\
\hline & Ratio in/af & & .795 & & \\
\hline
\end{tabular}

Explained variance: $R^{2}=79 \%$.

Table 4.

Effects of culture dimensions on context variables (stepwise regression).

\begin{tabular}{|c|c|c|c|c|}
\hline Dependent variable & Effects & $\begin{array}{l}\text { Adjusted } \\
R^{2}\end{array}$ & $\begin{array}{c}T \\
\text { value }\end{array}$ & $\begin{array}{c}p- \\
\text { Value }\end{array}$ \\
\hline \multicolumn{5}{|l|}{ GP } \\
\hline Gender & Wealth & $41 \%$ & 2.689 & .028 \\
\hline Job satisfaction & Uncertainty avoidance & $32 \%$ & -2.275 & .05 \\
\hline Risk-taking & Individualism/collectivism & $25 \%$ & 2.001 & .08 \\
\hline \multirow[t]{2}{*}{$\begin{array}{l}\text { Belief psychosocial } \\
\text { influence }\end{array}$} & Individualism/collectivism & $23 \%$, step & 3.368 & .012 \\
\hline & Uncertainty avoidance & $2^{52 \%, \text { step }}$ & 2.403 & .047 \\
\hline \multicolumn{5}{|l|}{ Patient } \\
\hline Gender & Individualism/collectivism & $47 \%$ & 2.980 & .018 \\
\hline Health condition & Wealth & $54 \%$ & 3.387 & .01 \\
\hline Psychosocial diagnosis & Wealth & $57 \%$ & 3.593 & .007 \\
\hline $\begin{array}{l}\text { Expectations, } \\
\text { biomedical }\end{array}$ & Individualism/collectivism & $82 \%$ & -6.572 & .000 \\
\hline $\begin{array}{l}\text { Expectations, } \\
\text { psychosocial }\end{array}$ & Power distance & $53 \%$ & 3.349 & .01 \\
\hline \multicolumn{5}{|l|}{ Consultation } \\
\hline Length & Wealth & $37 \%$ & 2.492 & .074 \\
\hline Patient utterances & Wealth & $30 \%$ & 2.221 & .057 \\
\hline Eye contact & Uncertainty avoidance & $42 \%$ & -2.729 & .026 \\
\hline
\end{tabular}


Meeuwesen, L., Brink, A. van den, Hofstede, G.

Can dimensions of national culture predict cross-national differences in medical

communication? Patient Education and Counseling: 2009, 75(1), 58-66

Table 5.

Effects of culture dimensions on verbal behaviour of physicians (stepwise regression).

\begin{tabular}{|c|c|c|c|c|}
\hline Dependent variable & Effects & $\begin{array}{l}\text { Adjusted } \\
R^{2}\end{array}$ & $t$ value & $\begin{array}{c}p \text { - } \\
\text { Value }\end{array}$ \\
\hline \multicolumn{5}{|l|}{ Affective } \\
\hline \multirow[t]{2}{*}{ Social talk } & Power distance & ${ }_{1}^{40 \%, \text { step }}$ & 2.917 & .02 \\
\hline & Masculinity & $2^{63 \%, \text { step }}$ & 2.493 & .04 \\
\hline \multirow[t]{3}{*}{ Agreement } & Individualism/collectivism & ${ }_{1}^{69 \%, \text { step }}$ & 2.810 & .021 \\
\hline & Power distance & $2^{80 \%, \text { step }}$ & -3.645 & .011 \\
\hline & Masculinity & $3^{89 \%, \text { step }}$ & 2.626 & .039 \\
\hline Rapport building & - & & & \\
\hline Facilitation & - & & & \\
\hline \multicolumn{5}{|l|}{ Instrumental } \\
\hline Orientation & Power distance & $27 \%$ & 2.095 & .069 \\
\hline Asking questions & Individualism/collectivism & $41 \%$ & -2.682 & .028 \\
\hline Giving information & Individualism/collectivism & $50 \%$ & 3.164 & .01 \\
\hline Counseling & Individualism/collectivism & $54 \%$ & -3.389 & .01 \\
\hline Biomedical talk & Masculinity & $45 \%$ & -2.867 & .02 \\
\hline Psychosocial talk & Uncertainty avoidance & $35 \%$ & 2.415 & .04 \\
\hline \multicolumn{5}{|l|}{ Ratios } \\
\hline $\begin{array}{l}\text { Ratio } \\
\text { biomedical/psychosocial }\end{array}$ & Uncertainty avoidance & $25 \%$ & 2.004 & .08 \\
\hline $\begin{array}{l}\text { Ratio } \\
\text { affective/instrumental }\end{array}$ & Individualism & $37 \%$ & -2.510 & .036 \\
\hline
\end{tabular}

Table 6.

Effects of culture dimensions on verbal behaviour of patients (stepwise regression). 
Meeuwesen, L., Brink, A. van den, Hofstede, G.

Can dimensions of national culture predict cross-national differences in medical communication? Patient Education and Counseling: 2009, 75(1), 58-66

\begin{tabular}{|c|c|c|c|c|}
\hline Dependent variable & Effects & $\begin{array}{l}\text { Adjusted } \\
R^{2}\end{array}$ & $t$ value & $\begin{array}{c}p- \\
\text { Value }\end{array}$ \\
\hline \multicolumn{5}{|l|}{ Affective } \\
\hline Social talk & Masculinity & $26 \%$ & 2.038 & .076 \\
\hline \multirow[t]{4}{*}{ Agreement } & Individualism/collectivism & ${ }_{1}^{41 \%, \text { step }}$ & 2.801 & .038 \\
\hline & Masculinity & $2^{73 \%, \text { step }}$ & 6.905 & .001 \\
\hline & Power distance & $390 \%$, step & -5.221 & .003 \\
\hline & Uncertainty avoidance & $4^{95 \%, \text { step }}$ & 2.487 & .005 \\
\hline Rapport building & - & & & \\
\hline Facilitation & Masculinity & $31 \%$ & 2.239 & .055 \\
\hline \multicolumn{5}{|l|}{ Instrumental } \\
\hline Asking questions & - & & & \\
\hline Giving information & Masculinity & $87 \%$ & -7.705 & .000 \\
\hline Biomedical talk & Masculinity & $65 \%$ & -4.201 & .003 \\
\hline Psychosocial talk & - & & & \\
\hline \multicolumn{5}{|l|}{ Ratios } \\
\hline $\begin{array}{l}\text { Ratio } \\
\text { biomedical/psychosocial }\end{array}$ & - & & & \\
\hline $\begin{array}{l}\text { Ratio } \\
\text { affective/instrumental }\end{array}$ & Masculinity & $47 \%$ & -2.983 & .018 \\
\hline
\end{tabular}

Table 7.

Effects of culture dimensions on the four main communication styles (stepwise regression). 
Meeuwesen, L., Brink, A. van den, Hofstede, G.

Can dimensions of national culture predict cross-national differences in medical communication? Patient Education and Counseling: 2009, 75(1), 58-66

\begin{tabular}{|c|c|c|c|c|}
\hline Factors & Effects & $\begin{array}{l}\text { Adjusted } \\
R^{2}\end{array}$ & $t$ value & $\begin{array}{c}p- \\
\text { Value }\end{array}$ \\
\hline $\begin{array}{l}\text { 1. Fixed communication } \\
\text { roles }\end{array}$ & Power distance & $72 \%$ & 4.874 & .001 \\
\hline $\begin{array}{l}\text { 2. Biomedical information } \\
\text { exchange }\end{array}$ & Masculinity & $64 \%$ & -4.089 & .003 \\
\hline 3. Rapport building & $\begin{array}{l}\text { Uncertainty } \\
\text { avoidance }\end{array}$ & $41 \%$ & -2.711 & .027 \\
\hline \multirow[t]{2}{*}{$\begin{array}{l}\text { 4. Psychosocial information } \\
\text { exchange }\end{array}$} & Wealth & $25 \%$, step & 2.739 & .029 \\
\hline & $\begin{array}{l}\text { Uncertainty } \\
\text { avoidance }\end{array}$ & $2^{44 \%, \text { step }}$ & 1.952 & .092 \\
\hline
\end{tabular}

